\title{
Spatial variability of POPs in European background air
}

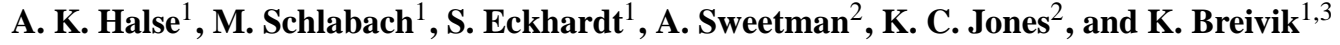 \\ ${ }^{1}$ Norwegian Institute for Air Research (NILU), P.O. Box 100, 2027 Kjeller, Norway \\ ${ }^{2}$ Department of Environmental Science, Institute of Environmental and Natural Sciences, Lancaster University, \\ Lancaster, LA1 4YQ, UK \\ ${ }^{3}$ University of Oslo, Department of Chemistry, P.O. Box 1033, 0315 Oslo, Norway
}

Received: 20 July 2010 - Published in Atmos. Chem. Phys. Discuss.: 1 October 2010

Revised: 7 January 2011 - Accepted: 4 February 2011 - Published: 17 February 2011

\begin{abstract}
Passive air samplers (PAS) were deployed at 86 European background sites during summer 2006 in order (i) to gain further insight into spatial patterns of persistent organic pollutants (POPs) in European background air and, (ii) to evaluate PAS as an alternative sampling technique under EMEP (Co-operative programme for monitoring and evaluation of the long-range transmissions of air pollutants in Europe). The samples were analyzed for selected PCBs, $\mathrm{HCHs}$, DDTs, HCB, PAHs and chlordanes, and air concentrations were calculated on the basis of losses of performance reference compounds. Air concentrations of PCBs were generally lowest in more remote areas of northern Europe with elevated levels in more densely populated areas. $\gamma-\mathrm{HCH}$ was found at elevated levels in more central parts of Europe, whereas $\alpha$ $\mathrm{HCH}, \beta-\mathrm{HCH}$ and DDTs showed higher concentrations in the south-eastern part. There was no clear spatial pattern in the concentrations for PAHs, indicative of influence by local sources, rather than long range atmospheric transport (LRAT). HCB was evenly distributed across Europe, while the concentrations of chlordanes were typically low or nondetectable. A comparison of results obtained on the basis of PAS and active air sampling (AAS) illustrated that coordinated PAS campaigns have the potential serve as useful inter-comparison exercises within and across existing monitoring networks. The results also highlighted limitations of the current EMEP measurement network with respect to spatial coverage. We finally adopted an existing Lagrangian transport model (FLEXPART) as recently modified to incorporate key processes relevant for POPs to evaluate potential source regions affecting observed concentrations at selected
\end{abstract}

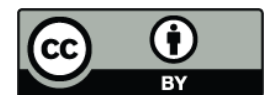

Correspondence to: $\mathrm{K}$. Breivik (kbr@nilu.no ) sites. Using PCB-28 as an example, the model predicted concentrations which agreed within a factor of 3 with PAS measurements for all except 1 out of the 17 sites selected for this analysis.

\section{Introduction}

Persistent organic pollutants (POPs) constitute a group of organic chemicals that are semi-volatile, bio-accumulative, persistent and toxic (e.g. Vallack et al., 1998). A key feature of these chemicals is their intrinsic potential for long range atmospheric transport (LRAT). Two international agreements have come into effect in order to protect human health and the environment from these substances. These are the global Stockholm Convention on POPs (UNEP, 2003) and the regional 1998 Aarhus Protocol on Persistent Organic Pollutants under the 1979 Geneva Convention on Long-range Transboundary Air Pollution (CLRTAP). The latter Protocol entered into force in 2003, and its ultimate goal is to eliminate any discharges, emissions and losses of POPs to the environment. The Aarhus Protocol initially focuses on 16 substances which include eleven pesticides, two industrial chemicals and three by-products/contaminants (UNECE, 1998).

Within EMEP (Co-operative programme for monitoring and evaluation of the long-range transmissions of air pollutants in Europe) the current measurement programme for POPs in air is based on a limited network of conventional active air samplers (AAS) at background sites, mainly located in the north-western part of Europe (Aas and Breivik, 2009) (Fig. S1 in Supplement). The high costs associated with AAS have in part motivated the development of passive air samplers (PAS). These samplers, which have become

Published by Copernicus Publications on behalf of the European Geosciences Union. 
increasingly popular over the last decade, have the potential to be used as a complimentary technique to conventional AAS (e.g. Shoeib and Harner, 2002b; Jaward et al., 2004a; Pozo et al., 2004; Harner et al., 2006b). Of key relevance to this study are the first European campaign using PAS (Jaward et al., 2004a, b) and the Global Atmospheric Passive Sampling (GAPS) studies (e.g. Pozo et al., 2009) which have measured POPs at both urban and rural sites on a European and global scale, respectively.

An important objective of this study has been to improve the knowledge of spatial patterns of POPs in background air across Europe using PAS. Altogether 92 samplers were deployed for $\sim 3$ months at 86 sites in 34 European countries during the late summer of 2006. Unlike the former European-wide survey carried out in 2002 (Jaward et al. 2004a,b), our main focus is on the occurrence of POPs across Europe in the context of LRAT. This study therefore targets background sites only. As PAS were mainly located at established EMEP sites which additionally monitor POPs using AAS on a regular basis, this study offered a unique opportunity to investigate similarities and differences in levels and patterns on the basis of complementary air measurements.

The results of these investigations are also used to discuss limitations of the current EMEP measurement network with respect to spatial coverage. These results may also be used to evaluate LRAT models, both within EMEP (e.g. Malanichev et al., 2004) and beyond. As an illustration, we have also included an assessment of differences in predicted source-receptor relationships at selected sites as exemplified for PCB-28, using an existing model (Eckhardt et al., 2009).

\section{Materials and methods}

\subsection{Theory}

Polyurethane foam (PUF) disks have gained increasing use as PAS (Shoeib and Harner, 2002b; Harner et al., 2004, 2006b; Jaward et al., 2004a; Pozo et al., 2004, 2006; Motelay-Massei et al., 2005). These PUF disks have high affinity and capacity to sorb organic chemicals. Accumulation of a chemical during exposure is equivalent to the rate of uptake minus rate of loss. Uptake of POPs is airside controlled and is initially linear and a function of the mass transfer coefficient $\left(k_{A}\right)$, the planar area of the sampling media $\left(A_{\mathrm{PSM}}\right)$ and concentration of the compound in air $\left(C_{\mathrm{A}}\right)$. Ideally, these are the functioning conditions to the sampler out in the field, but as the chemical builds up in the sampling medium, the rate of uptake will be reduced and finally reach equilibrium (Shoeib and Harner, 2002b). The duration of the linear phase is dependent on the octanol-air partition coefficient $\left(K_{\mathrm{OA}}\right)$, and chemicals with low $K_{\mathrm{OA}}$ will reach equilibrium with the atmosphere faster than chemicals with higher $K_{\mathrm{OA}}$ (Harner et al., 2004). Uptake is also found to increase at elevated wind speeds, as this causes an increase in the mass transfer coefficient $\left(k_{A}\right)$ (Tuduri et al., 2006).

The PUF disk sampler typically contains a PUF foam disk placed between two stainless steel metal domes in a so called "flying saucer" design (Wilford et al., 2004). This design aims to protect the foam disk from precipitation, sunlight, wind speed effects and coarse particle deposition. Air flows through a gap between the two domes (Pozo et al., 2004). Different passive sampler housings have been tested, and a relatively recent study (Tuduri et al., 2006), shows that the "flying saucer" design dampens the wind speed effect adequately. The specific housing design used in this study with metal tubes inside the sampler, offers the additional advantage that the width of the gap between the two domes is kept identical from site to site.

The PUF disks were spiked with depuration compounds (Performance Reference Compounds - PRCs) of different volatility prior to exposure (Huckins et al., 2002), which were either isotopically labelled or other non-native compounds. The loss rate of PRCs experienced during deployment are in turn used to back-calculate air concentrations in the PAS (e.g. Tuduri et al., 2006).

\subsection{Deployment and sample preparation}

Samplers were exposed in the field for about 3 months in various European countries in a coordinated campaign during late summer 2006. The study region included 34 countries and 86 sites, located from Spitsbergen $\left(78^{\circ} \mathrm{N}\right)$ in the north to Cyprus $\left(33^{\circ} \mathrm{N}\right)$ in the south, and from Greenland $\left(38^{\circ} \mathrm{W}\right)$ in the west to Kazakhstan $\left(75^{\circ} \mathrm{E}\right)$ in the east (see Table S1). Most of the sites included in this study $(\mathrm{N}=71)$ are part of the EMEP measurement network (see e.g. Aas and Breivik, 2008) although additional remote sites $(\mathrm{N}=15)$ were included to improve spatial coverage in certain regions. PAS were additionally co-deployed with AAS at EMEP sites (Fig. S1) where POPs are monitored under EMEP on a routine basis to evaluate possible differences in results, along with duplicated PAS samplers and field blanks.

\subsection{Analysis}

In the following section, only a brief overview of the sample treatment and analysis will be given. More detailed information of the sample preparation, including pre-cleaning and clean-up of the PUF disks and analysis is presented in the Supplement.

The PUF disks were pre-cleaned by soxhlet extraction, dried and spiked with PRCs prior deployment, and returned to the laboratory for clean-up and analysis after end of deployment ( $\sim 3$ months) (Supplement S1.1). A mixture of internal standards was added to the PUFs before Soxhlet extraction and further clean-up. The cleanup procedure involves separation into two extracts, with acid treatment and silica fractionation for analysis of the 
persistent compounds, and silica fractionation for the $\mathrm{PAH}$ extract (Supplement S1.2). The extracts were further concentrated by a gentle stream of nitrogen to $\sim 50 \mu \mathrm{L}$ and added recovery standards (Supplement S1.3). Identification and quantification of individual substances was carried out using a gas chromatograph coupled to a high resolution (PCBs, $\mathrm{HCHs}, \mathrm{HCB}, \mathrm{DDTs}$ ) and low resolution (PAHs, chlordanes) mass spectrometer, with gas chromatograph conditions as explained in Supplement (Table S3, Supplement S1.3).

\subsection{Deriving concentrations in air/effective air sample volume}

In order to back-calculate the actual air concentrations for individual compounds in air, information on the PUF characteristics, air temperature, measured loss of individual PRCs and their temperature dependent $\mathrm{K}_{\mathrm{OA}}$-values were used in an initial step to calculate site-specific sampling rates (e.g. Shoeib and Harner, 2002b; Pozo et al., 2004, 2009). The average air temperatures at each site for the exposure period are based on meteorological data from European Centre for Medium-Range Weather Forecasts (ECMWF) to ensure a consistent approach. Here, at 2 meter above ground level, the temperature was averaged every 3 hour over the period for which the respective sample was taken. The altitude for each site (Table S1) was next compared against the model altitude. For five high altitude sites where large differences were noted (Jungfraujoch, Moussala, Zavizan, Chopok and Longobucco), the ECMWF data were adjusted by assuming a temperature decrease by altitude of $-0.65^{\circ} \mathrm{C}$ per $100 \mathrm{~m}$. Loss of PRCs from individual samples was estimated on the basis of the ratio between the amount of PRCs in individual samples and the average amount of PRCs in the field blanks. For PCBs $(23,30,32,107,198)$, temperature dependent $\mathrm{K}_{\mathrm{OA}}$-values were derived on the basis of data reported by Harner and Bidleman (1996) and relative retention times from Harju et al. (1998). For PCB-12 and -14, we used data from $\mathrm{Li}$ et al. (2003), and for D6 $\gamma-\mathrm{HCH}$, information presented by Shoeib and Harner (2002a). Only PRCs which experienced a loss of $40 \%$ or more were used to calculate an average site-specific sampling rate (Pozo et al., 2009). The resulting sampling rates and number of PRCs used in these calculations are presented in Table S1. These sampling rates were then used to convert measured values into air concentration by dividing the amounts in the sampler by the effective air volumes as detailed by Shoeib and Harner (2002b). For a few sites experiencing insufficient loss of the PRCs (Nuuk, Summit, Spitsbergen, Sniezka), the default sampling rate proposed by Harner et al. (2006c) was used to estimate effective air volumes for individual substances. The resulting air concentrations for these sites should therefore be interpreted with caution.

\subsection{Model}

Simulations of atmospheric POP transport were made using the Lagrangian particle dispersion model FLEXPART (Stohl et al., 1998, 2005; Stohl and Thomson, 1999). FLEXPART was driven with analyses from the European Centre for Medium-Range Weather Forecasts (ECMWF, 1995) with $1^{\circ} \times 1^{\circ}$ resolution (derived from T319 spectral truncation). Analyses at 00:00, 06:00, 12:00 and 18:00 UTC, and 3-h forecasts at 03:00, 09:00, 15:00 and 21:00 UTC were used. There are 23 ECMWF model levels below $3000 \mathrm{~m}$, and 91 in total. FLEXPART calculates the trajectories of so-called tracer particles and accounts for turbulence, convection, deposition (wet and dry) and atmospheric reaction by hydroxyl (OH) radicals (Eckhardt et al., 2009). It was run in backward mode, in order to identify the source regions of air pollutants at a particular site (Stohl et al., 2003; Seibert and Frank, 2004). These were found by following all 4 million particles equally released over the sample duration, 20 days backward in time. These source regions are expressed as emission sensitivities (ES) in the footprint layer (0-100 $\mathrm{m}$ above ground) during each deployment period at different sites. The ES unit is nanoseconds per cubic meter, which is the residence time of air masses normalized by the volume. The ES maps for the footprint layer thus illustrates were the air mass had the ability to collect pollutants from sources near the ground. Multiplying this ES with emission fluxes from the PCB-28 emission inventory (Breivik et al., 2007) yields the geographical distribution of sources contributing to the simulated concentration at the given measurement site. Emission contributions (EC), which gives the simulated air concentration at the receptor, may then be obtained by areal integration. For further details we refer to the original publications listed above.

\section{Quality Assurance/Quality Control (QA/QC)}

The analytical procedures were monitored using NS/EN ISO/IEC 17025 accredited routines for quality assurance and quality control. A calibration solution was injected after every fourth sample, and was used to quantify the samples. Regarding PCBs, HCHs, DDTs, HCB and the chlordanes, a standard reference material (SRM 1588) from the National Institute of Standards and Technology (NIST) containing organic compounds in cod liver oil was analyzed routinely. In addition, for the quantification control, the retention for ${ }^{12} \mathrm{C}$ labeled compound should not be more than 3 seconds later than its corresponding ${ }^{13} \mathrm{C}$-labeled isomer. Furthermore the isotope ratio based on a 3:1 relationship between ${ }^{12} \mathrm{C}$ and

${ }^{13} \mathrm{C}$, for the two monitored masses, must be within $\pm 20 \%$ of the theoretical value. For the PAHs, the SRM solution, SRM 1491 (NIST) was analyzed during each run. 
Table 1. Concentrations of selected PCBs, HCHs, DDTs, chlordanes and HCB $\left(\mathrm{pg} \mathrm{m}^{-3}\right)$ and selected PAHs (ng m $\left.{ }^{-3}\right)$ at European background sites.

\begin{tabular}{|c|c|c|c|c|c|c|c|}
\hline \multirow[b]{2}{*}{ Compounds } & \multicolumn{6}{|c|}{ Measured range } & \multirow[b]{2}{*}{$\begin{array}{l}\mathrm{Max} / \mathrm{min} \\
\text { ratio }(\mathrm{MMR})\end{array}$} \\
\hline & $\begin{array}{r}\text { Average } \\
\pm \text { S.D }\end{array}$ & Median & $\begin{array}{r}\text { Deployed } \\
\text { samples }\end{array}$ & Blanks & MDL & $\begin{array}{c}\% \text { above } \\
\text { MDL }\end{array}$ & \\
\hline PCB-28 & $5 \pm 4$ & 4 & $0.6-20$ & $0.06-0.3$ & 0.4 & 100 & 34 \\
\hline PCB-52 & $5 \pm 4$ & 4 & $0.8-20$ & $0.05-0.3$ & 0.3 & 100 & 25 \\
\hline PCB-101 & $4 \pm 5$ & 3 & $0.4-34$ & $0.03-0.3$ & 0.3 & 100 & 84 \\
\hline PCB-118 & $1.5 \pm 1.5$ & 1.0 & $0.2^{\mathrm{a}}-8.3$ & $0.001^{b}-0.2$ & 0.2 & 95 & $>55$ \\
\hline PCB-138 & $2.0 \pm 2.4$ & 1.2 & $0.2^{\mathrm{a}-18.3}$ & $0.001^{b}-0.2$ & 0.2 & 95 & $>102$ \\
\hline PCB-153 & $3 \pm 4$ & 2 & $0.3^{\mathrm{a}-28}$ & $0.004^{\mathrm{b}}-0.3$ & 0.3 & 94 & $>87$ \\
\hline PCB-180 & $0.8 \pm 0.9$ & 0.6 & $0.05^{\mathrm{a}}-6$ & $0.001-0.04$ & 0.05 & 98 & $>122$ \\
\hline$\Sigma_{7} \mathrm{PCBs}$ & $21 \pm 19$ & 17 & $2-121$ & & & & $>55$ \\
\hline$\alpha-\mathrm{HCH}$ & $26 \pm 24$ & 21 & $5-156$ & $0.1-0.8$ & 1 & 100 & 33 \\
\hline$\beta-\mathrm{HCH}$ & $2 \pm 7$ & 1 & $0.13^{\mathrm{a}}-49$ & $0.01-0.2$ & 0.13 & 85 & $>380$ \\
\hline$\gamma-\mathrm{HCH}$ & $35 \pm 38$ & 19 & $1.8-170$ & $0.1-1.3$ & 1.3 & 100 & 94 \\
\hline$\Sigma_{3} \mathrm{HCHs}$ & $64 \pm 59$ & 46 & $9-311$ & & & & $>36$ \\
\hline$p, p^{\prime}$-DDE & $21 \pm 47$ & 6 & $1.6^{\mathrm{a}}-281$ & $0.06-2$ & 1.6 & 74 & $>177$ \\
\hline$p, p^{\prime}-\mathrm{DDD}$ & $0.5 \pm 1.1$ & 0.2 & $0.06^{\mathrm{a}}-10$ & $0.004^{b}-0.07$ & 0.06 & 79 & $>169$ \\
\hline$o, p^{\prime}$-DDT & $4 \pm 7$ & 2 & $0.3^{\mathrm{a}}-39$ & $0.001^{b}-0.3^{d}$ & 0.3 & 87 & $>143$ \\
\hline$p, p^{\prime}$-DDT & $6 \pm 9$ & 2 & $0.2^{\mathrm{a}-46}$ & $0.001^{b}-0.2$ & 0.2 & 86 & $>240$ \\
\hline$\Sigma_{4}$ DDTs & $32 \pm 62$ & 10 & $1.1-356$ & & & & $>312$ \\
\hline Fluorene & $1.7 \pm 1.8$ & 1.0 & $0.1^{\mathrm{a}-9.7}$ & $0.01^{\mathrm{b}}-0.1$ & 0.1 & 98 & $>83$ \\
\hline Phenanthrene & $3 \pm 3$ & 2 & $0.1^{\mathrm{a}}-20$ & $0.01^{\mathrm{b}}-0.1$ & 0.1 & 95 & $>147$ \\
\hline Anthracene & $0.07 \pm 0.1$ & 0.03 & $0.007^{\mathrm{a}}-0.9$ & $0.007^{\mathrm{c}}$ & 0.007 & 88 & $>130$ \\
\hline Fluoranthene & $0.7 \pm 0.8$ & 0.4 & $0.03^{\mathrm{a}}-3.5$ & $0.01^{\mathrm{b}}-0.03$ & 0.03 & 95 & $>117$ \\
\hline Pyrene & $0.4 \pm 0.4$ & 0.2 & $0.02^{\mathrm{a}}-2.4$ & $0.01^{\mathrm{b}}-0.02$ & 0.02 & 99 & $>153$ \\
\hline Benz[a]anthracene & $0.02 \pm 0.03$ & 0.01 & $0.004^{\mathrm{a}}-0.2$ & $0.005^{\mathrm{c}}$ & 0.004 & 68 & $>49$ \\
\hline Chrysene & $0.07 \pm 0.07$ & 0.03 & $0.004^{\mathrm{a}}-0.3$ & $0.004^{\mathrm{c}}$ & 0.004 & 95 & $>58$ \\
\hline Benzo[a]pyrene & $0.008 \pm 0.01$ & 0.002 & $0.004^{\mathrm{a}}-0.06$ & $0.004^{\mathrm{c}}$ & 0.004 & 43 & $>15$ \\
\hline$\Sigma_{8} \mathrm{PAHs}$ & $6 \pm 6$ & 4 & $0.2-35$ & & & & $>205$ \\
\hline $\mathrm{HCB}$ & $49 \pm 18$ & 45 & $23-115$ & $0.2-3$ & 3 & 100 & 5 \\
\hline trans-chlordane & $0.8 \pm 1.1$ & 0.4 & $0.07^{\mathrm{a}}-7.3$ & $0.003^{\mathrm{e}}-0.1$ & 0.07 & 95 & $>104$ \\
\hline cis-chlordane & $1.2 \pm 0.7$ & 1.2 & $0.1^{\mathrm{a}}-4.6$ & $0.006^{\mathrm{e}}-0.1$ & 0.1 & 98 & $>46$ \\
\hline trans-nonachlor & $1.3 \pm 1.0$ & 1.2 & $0.1^{\mathrm{a}-7.0}$ & $0.002^{\mathrm{e}}-0.08$ & 0.1 & 98 & $>77$ \\
\hline cis-nonachlor & $0.16 \pm 0.1$ & 0.15 & $0.05^{\mathrm{a}}-0.5$ & $0.001^{\mathrm{e}}-0.04$ & 0.05 & 87 & $>11$ \\
\hline$\Sigma_{4}$ chlordanes & $3.5 \pm 2.7$ & 3.2 & $0.2-19.4$ & & & & $>114$ \\
\hline
\end{tabular}

${ }^{a}$ MDL (method detection limit) ${ }^{b}$ The lower limit is $1 / 2$ of the IDL (instrument detection limit) ${ }^{c}$ The component were not detected in the blanks ${ }^{d}$ Interference in one of the blanks ${ }^{\mathrm{e}}$ Lower and upper concentrations in the blanks were below IDL

\subsection{Method and field blanks values}

Method and field blanks consisted of pre-cleaned PUF disks which were extracted and analyzed in the same way as the exposed samples. Method blanks were only stored at NILU, whereas field blanks were brought in field with the deployed samples but not exposed. The field and method blank values were converted into an air concentration by using the average sampling rate $\left(4.9 \mathrm{~m}^{3} \mathrm{day}^{-1}\right)$, temperature $\left(14^{\circ} \mathrm{C}\right)$ and exposure time (94 days). The method and field blank values had similar values.

\subsection{Method detection limit (MDL)}

The method detection limit (MDL) was calculated as the average of the field and method blank concentrations $(\mathrm{N}=18)$ plus 3 times the standard deviations (SD) (Table 1).When the target compound was not detected in the blanks (method blank and field blank), an instrumental detection limit (IDL) value derived from signal/noise values 3:1 divided by two, was used to derive a MDL (Pozo et al., 2009). This was not the case for the PAHs, where the lowest measured ranges for air samples for the instrument were $0.01-0.02 \mathrm{ng} \mathrm{m}^{-3}$. 
For the components studied here (fluorene - benzo(a)pyrene) only $0.01 \mathrm{ng} \mathrm{m}^{-3}$ was used. For values that fell below this limit, half of this measured value was used. Furthermore, when the target compound in the exposed samples fell below the calculated method detection limit (MDL), half of the MDL from the field and method blanks was used for statistical treatment (Pozo et al., 2009). Table 1 provides more information regarding the blanks.

\subsection{Recoveries}

Two types of recoveries were compiled, namely recovery of the internal standards and of the PRCs. Quantification of the analytes is based on the added ${ }^{13} \mathrm{C}$ or ${ }^{2} \mathrm{D}$-labeled internal standards and therefore the results must not be corrected for low recoveries. Recovery rates are listed and discussed in the Supplement (S1.4, S1.5 and Table S2).

The concentrations were not blank corrected due to both low and not stable concentrations in the blanks, whereas they were automatically corrected for the recoveries.

\subsection{Uncertainties in the chemical analysis}

Different factors influence the uncertainty in the chemical analysis: loss during sample extraction and clean-up, accuracy of the standard concentrations, instrumental parameters, in addition to interferences from other compounds and possible sample contamination. To compensate for possible loss of analytes due to sample clean-up, internal standards were used in combination with a recovery standard. Field blanks were used to evaluate possible contamination during transport, and the method blanks to evaluate the laboratory conditions (e.g. solvents, adsorbents) respectively. Different approaches were applied to quantify these uncertainties, i.e. performance of intra laboratory/inter laboratory experiments and a critical step-by-step evaluation of all analytical steps. Both approaches result in a similar estimate for the uncertainty of the chemical analysis in the range of $20-35 \%$, but will vary for different compounds/groups.

\subsection{Uncertainties in back-calculated PAS air concentrations}

The PAS results are converted into air concentrations, rather than presented as sequestered amount per sampler, as this is essential to facilitate a direct comparison with both AAS results (4.2.1) and model outputs (4.4). The use of backcalculated air concentrations introduces additional uncertainties which are likely to exceed those that are associated with the chemical analysis alone (3.4). Past evaluations has suggested that the PAS method enables estimates of "true" air concentrations within a factor of 2-3 (Gouin et al., 2005a; Harner et al., 2006a; Klanova et al., 2008). Errors in estimated air concentrations reflect in part uncertainties in input parameters used to calculate uptake rates (e.g. Shoeib and Harner, 2002a), such as octanol-air partition coefficients and their temperature dependencies (e.g. Li et al., 2003), the use of modeled rather than measured chamber air temperatures (Kennedy et al., 2010), and in the selection/loss of PRCs (e.g. Bartkow et al., 2006a; Moeckel et al., 2009). Furthermore, there are uncertainties associated with sampling performance under variable environmental conditions, such as elevated wind speeds (Tuduri et al., 2006; Chaemfa et al., 2009b), sun-light intensity (Bartkow et al., 2006b), humidity (Santiago and Cayetano, 2007), temperatures (Klanova et al., 2008) and potential artifacts caused by inadvertent particle-phase sampling of POPs (e.g. Klanova et al., 2008; Chaemfa et al., 2009b). To further characterize uncertainties associated with uptake rates, a range of different field studies have previously been carried out whereby results obtained on the basis of AAS and PAS have been compared and contrasted (e.g. Gouin et al., 2005a, 2008; Klanova et al., 2008; Chaemfa et al., 2008, 2009a; Moeckel et al., 2009; Hayward et al., 2010). We refer to these studies for a more detailed account of uncertainties in uptake rates.

\section{Results and discussion}

\subsection{Overall results}

Table 1 shows the calculated air concentrations (average, median, range) of selected POPs at European background sites $(\mathrm{N}=86)$, while data for individual sites are included in the Supplement. PCBs 28, 52, 101, $\alpha$ - and $\gamma-\mathrm{HCH}$ and $\mathrm{HCB}$ were detected in all samples, while some samples were below the method detection limit (MDL) for all other compounds. The spatial variability in the overall results is initially evaluated by the ratio between maximum and minimum air concentrations (MMR). For samples with concentrations below the MDL, the minimum concentration was replaced by the MDL when calculating the MMR and set to $1 / 2$ MDL for the calculation of average, and median air concentrations in Table 1.

\section{PCBs}

The average concentration of $\Sigma_{7} \mathrm{PCBs}$ was $21 \mathrm{pg} \mathrm{m}^{-3}$ $\left(\mathrm{SD} \pm 19 \mathrm{pg} \mathrm{m}^{-3}\right)$. The most abundant PCBs were PCB-52, $-28,-101$ and -153 which contributed $23 \%, 22 \%, 20 \%$ and $15 \%$ to the average concentration of $\Sigma_{7} \mathrm{PCBs}$, respectively. $\Sigma_{7}$ PCBs has a MMR of more than 55 which shows that there is still a marked spatial variability, even across European background sites. This may be interpreted as a continuing influence of primary emissions on atmospheric levels. Alternatively, it cannot be excluded that some of the sites have been influenced by the presence of one or more local emission sources. The range is anyhow smaller than previously reported for $\Sigma_{29} \mathrm{PCBs}$ in a similar study across Europe in 2002 (Jaward et al., 2004a). The former study reported a variability of more than 2 orders of magnitude between the 
highest and lowest samples, but included a combination of both urban areas as well as remote background sites. MMR furthermore tended to increase with increasing chlorination (Table 1), suggesting lighter PCBs to be more evenly distributed in European background air in comparison to their heavier counterparts. This may in part be seen as a reflection of a more limited long-range atmospheric transport potential of heavier PCBs, causing larger variability in air concentrations (and thus MMR) for these substances (Wania and Daly, 2002).

\section{HCHs}

The average concentration of $\Sigma_{3} \mathrm{HCHs}(\alpha, \beta, \gamma)$ was $64 \mathrm{pg} \mathrm{m}^{-3}\left(\mathrm{SD} \pm 59 \mathrm{pg} \mathrm{m}^{-3}\right)$. The concentration of $\Sigma_{3} \mathrm{HCHs}$ varied from 9-311 $\mathrm{pg} \mathrm{m}^{-3}$, with $\gamma-\mathrm{HCH}$ and $\alpha-\mathrm{HCH}$ contributing on average $55 \%$ and $41 \%$, respectively. $\beta$ - $\mathrm{HCH}$, which was close to MDL in some samples (Table 1), was less abundant and contributed only $4 \%$ on average. The median concentrations of $\gamma-\mathrm{HCH}$ and $\alpha-\mathrm{HCH}$ were similar, although the average concentration for $\gamma-\mathrm{HCH}\left(35 \mathrm{pg} \mathrm{m}^{-3}\right)$ was higher than for $\alpha-\mathrm{HCH}\left(26 \mathrm{pg} \mathrm{m}^{-3}\right)$. This illustrates a more homogenous distribution of $\alpha-\mathrm{HCH}$ in European background air in comparison to $\gamma-\mathrm{HCH}$, as also illustrated by the MMR for these two HCH isomers (Table 1). $\gamma-\mathrm{HCH}$ is less volatile than $\alpha-\mathrm{HCH}$ (Xiao et al., 2004), which in turn may help to explain observed differences in air concentrations and environmental fates between the two isomers (Breivik and Wania, 2002). The results for $\beta-\mathrm{HCH}$ should be interpreted with caution as several samples $(\mathrm{N}=13)$ were below MDL (Table 1). However, the large spatial variability for this isomer (MMR > 380) suggests a highly skewed distribution. This is noteworthy and may in part be attributed to the fact that $\beta-\mathrm{HCH}$ is much more water-soluble than the other two isomers and hence more easily subject to wash-out by rain in spite of a similar emission history to $\alpha$-HCH (Li et al., 2002).

\section{DDTs}

The average concentration of $\Sigma_{4}$ DDTs was $32 \mathrm{pg} \mathrm{m}^{-3}$ $\left(\mathrm{SD} \pm 62 \mathrm{pg} \mathrm{m}^{-3}\right)$, and ranged from $1.1 \mathrm{pg} \mathrm{m}^{-3}$ to $356 \mathrm{pg} \mathrm{m}^{-3}$ with $p, p^{\prime}-\mathrm{DDE}$ as the major contributing isomer $(67 \%$ on average). The second most prominent isomer was $p, p^{\prime}-\mathrm{DDT}$ with an average contribution of 18\%. MMRs were all high within the group of DDTs and ranged from $>143\left(o, p^{\prime}-\mathrm{DDT}\right)$ to $>240\left(p, p^{\prime}-\mathrm{DDT}\right)$.

\section{PAHs}

The average concentration of $\Sigma_{8}$ PAHs was $6 \mathrm{ng} \mathrm{m}^{-3}$ $\left(\mathrm{SD} \pm 6 \mathrm{ng} \mathrm{m}^{-3}\right)$ and ranged from $0.2-35 \mathrm{ng} \mathrm{m}^{-3}$. The more abundant PAHs include phenanthrene and fluorene which each contributed on average $49 \%$ and $29 \%$, respectively. As expected, the contribution from heavier PAHs, such as benz(a)anthracene, chrysene and benzo(a)pyrene, was typically low with average contributions of $0.35 \%$. $1.2 \%$ and $0.14 \%$ to $\Sigma_{8}$ PAHs, respectively. This is also consistent with earlier studies (e.g. Halsall et al., 1994; Lohmann et al., 2000). MMR furthermore ranged from $>15$ (benzo(a)pyrene) to $>153$ (pyrene). The results for $\Sigma_{8}$ PAHs compares favourably with similar results from the previous European campaign by Jaward et al. (2004b), which reported a measured range between 0.004 and $26 \mathrm{ng} \mathrm{m}^{-3}$ for the same PAHs and also noted that lighter PAHs tended to dominate in the samples since they occur in the gas-phase and hence have higher ability for transport, while heavier PAHs (benzo(a)pyrene) are more related to the particle phase (Lohmann et al., 2000).

\section{HCB}

HCB was detected in all samples with an average concentration of $49 \mathrm{pg} \mathrm{m}^{-3}\left(\mathrm{SD} \pm 18 \mathrm{pg} \mathrm{m}^{-3}\right.$; range: $\left.23-115 \mathrm{pg} \mathrm{m}^{-3}\right)$. The variability was limited with a MMR of 5 , very similar to what has been previously reported for Europe (Jaward et al., 2004a). This has been interpreted as evidence of the long atmospheric lifetime of this volatile compound, combined with the absence of significant point sources of HCB in Europe (Jaward et al., 2004a). However, similar studies in Asia have reported larger variability, indicative of continuing emissions (Jaward et al., 2005). We also note that the range in air concentrations reported here (23$115 \mathrm{pg} \mathrm{m}^{-3}$ ) are higher than previously reported for Europe (11-50 $\mathrm{pg} \mathrm{m}^{-3}$ ) by Jaward et al. (2004a). Interestingly, a recent study on levels and trends of POPs in Arctic air suggest an increase in $\mathrm{HCB}$ in recent years, and attribute this to a potential increase in worldwide usage of certain pesticides contaminated with HCB (Hung et al., 2010).

\section{Chlordanes}

The average concentration for the $\Sigma_{4}$ chlordanes was $3.5 \mathrm{pg} \mathrm{m}^{-3}\left(\mathrm{SD} \pm 2.7 \mathrm{pg} \mathrm{m}^{-3}\right)$. The concentrations varied from $0.2 \mathrm{pg} \mathrm{m}^{-3}$ to $19.4 \mathrm{pg} \mathrm{m}^{-3}$, with trans-nonachlor and cis-chlordane contributing $38 \%$ and $35 \%$, respectively. The least abundant compound was cis-nonachlor with 5\%. Concentrations of individual chlordanes were typically low in comparison to the other substances studied and MMR ranged from $>11$ (cis-nonachlor) to $>104$ (trans-chlordane).

\subsection{Duplicate passive air sampling and comparison with active air sampling}

Two passive air samplers were co-deployed close to each other at each EMEP-site where POPs are monitored on a regular basis using conventional AAS techniques 

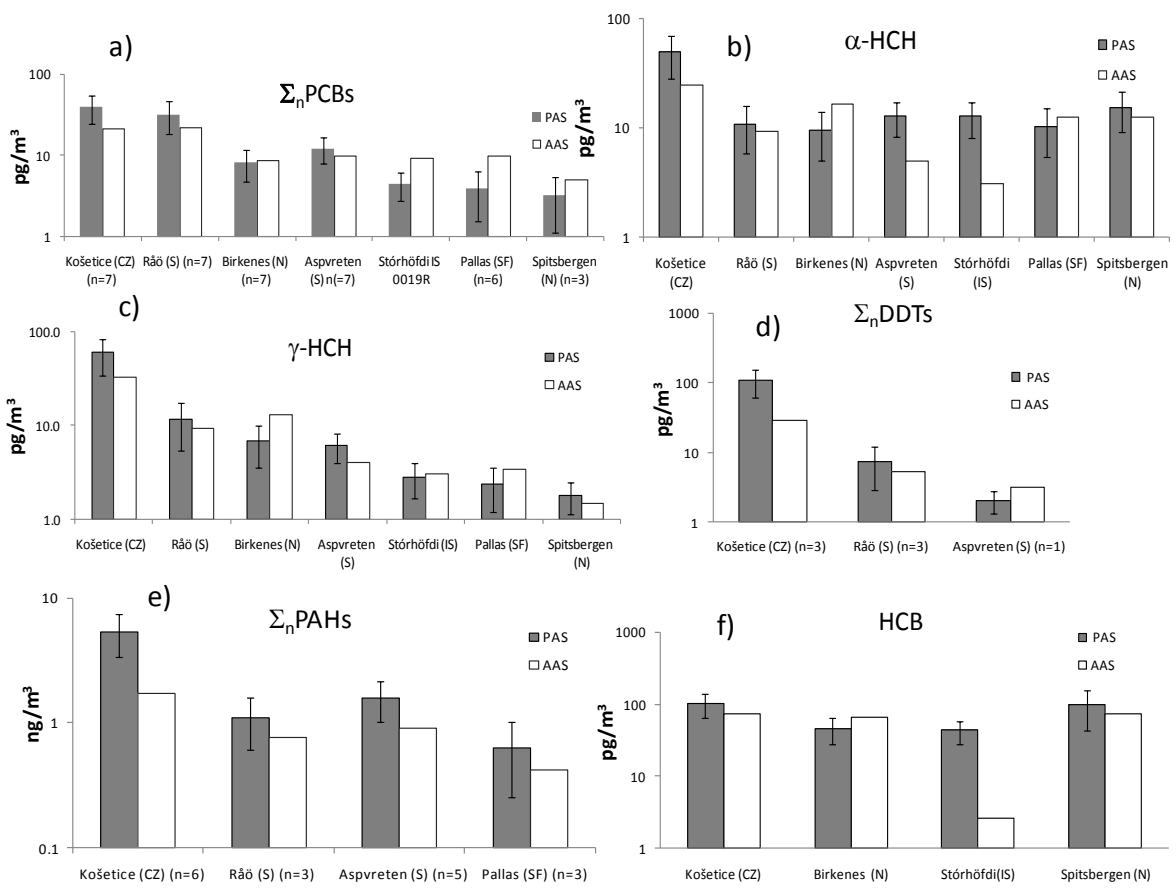

Fig. 1. (a)-(f): Comparison of results obtained on the basis of PAS (average of two parallels) and AAS (see text for details).

(Košetice, Pallas, Stórhöfdi, Birkenes, Spitsbergen, Råö, Aspvreten) (Aas and Breivik, 2008), see also Fig. S1. This was done to gain further insights into the reproducibility of the PAS method (e.g. Harner et al., 2006b) as further discussed in the Supplement (Supplement S1.6), and to evaluate possible differences between PAS and AAS results (e.g. Gouin et al., 2005a, b; Mari et al., 2008). Regrettably, one of the samplers from the Aspvreten site was lost. The comparison for this EMEP AAS site is thus restricted to one PAS sample only.

\subsubsection{Passive air sampling in comparison with active air samplers}

One of the objectives of this study has been to further assess the potential of PAS as a complementary technique to conventional AAS within the EMEP monitoring program. For this purpose direct comparisons of results obtained on the basis of AAS and PAS have been carried out. Although such comparisons have been reported previously (Gouin et al., 2005a; Mari et al., 2008), past evaluations of this kind have typically been carried out on the basis of results obtained at the same chemical laboratory. In this work, AAS results are mainly obtained on the basis of results originating from different chemical laboratories, hence both intra and inter laboratory uncertainties must be taken into account. Exceptions to this are the samples from the two Norwegian sites (Birkenes and Spitsbergen) which were both analyzed at the NILU laboratories. We should further note that the AAS monitoring strategies within EMEP vary in terms of both sampling durations and frequencies and hence temporal cov- erage (Table S5). Only Stórhöfdi and Råö collect samples on a continuous basis, while Košetice, Birkenes, Aspvreten, Pallas and Spitsbergen have sampling coverage of less than $30 \%$ (Table S5). A direct comparison between AAS and PAS for the latter five EMEP sites is therefore difficult as the different samplers have been exposed to different air masses. AAS and PAS sampling strategies are also fundamentally different as data obtained on the basis of AAS typically represent the sum of the particulate and gaseous air concentrations. Finally, we note again that all results for Spitsbergen obtained on the basis of PAS in this study may be questioned as they rely on the default uptake rate (2.4).

Concentrations from the AAS were averaged over the same sampling period (or as close as possible) as for the passive air samplers (i.e. 3 months). The average air concentrations for the two PAS parallels from each EMEP site were used. Figure 1a-f illustrates the absolute differences between PAS and AAS results. The error bars included in Fig. 1 represent an estimate of the cumulative uncertainty associated with both the chemical analysis $( \pm 35 \%)$ plus the relative deviations between the two parallels (Table S4). However, the latter source of uncertainty is not captured for Spitsbergen as this site relies on the default sampling rate (Table S1) as well as Aspvreten which is based on one PAS sample only. Thus, whenever significant difference are observed in Fig. 1 (with the exception of the two sites noted), the more plausible explanations may be that these differences are caused by (i) sampling of different air masses, or (ii) analysis of the samples by different laboratories. 
Relative deviations for individual substances, expressed as $\left(\mathrm{C}_{\mathrm{PAS}}-\mathrm{C}_{\mathrm{AAS}}\right) / \mathrm{C}_{\mathrm{AAS}}$, are additionally included in Table $\mathrm{S} 5$ whereby a positive deviation illustrates higher concentration in the PAS, relative to the AAS.

\section{PCBs}

The percentage deviation relative to AAS results varied from $-59 \%$ (Pallas) up to $+86 \%$ (Košetice) for $\Sigma_{n}$ PCBs, where $\mathrm{n}$ denotes the number of congeners (see Table S5). Larger relative deviations were observed for some congeners and sites, such as PCBs $101(+178 \%), 138(257 \%)$ and $153(193 \%)$ at Košetice. One possible explanation for the large deviations seen at the Košetice site is that the AAS is only operating one day per week (Table S5) and hence the air masses sampled deviate significantly between the AAS and the PAS. This effect may be particularly significant at Košetice as this site is located close to major source regions in Europe (Breivik et al., 2007). Air concentrations at this site may thus be expected to fluctuate significantly over time as the air masses would be expected to be less well-mixed. This issue is further explored for PCB-28 in Sect. 4.4. However, if difference in sampling coverage was the only factor to consider, significant deviations would also be expected at those other sites which do not operate the AAS on a continuous basis (Birkenes, Aspvreten, Pallas and Spitsbergen). The best agreement between AAS and PAS for $\Sigma_{n}$ PCBs was obtained for Birkenes (-5\%) (Table S5), which may be due to a combination of air concentrations being well above MDL and the fact that the samples being analyzed at the same chemical laboratory. The latter may indeed represent an important factor to consider as it has recently been indicated that differences up to a factor of 2 can be expected for atmospheric samples of semi-volatile organic compounds when comparing results from different laboratories (Su and Hung, 2010). It must be cautioned that this comparison is of limited significance for Spitsbergen and Pallas as some PAS results were close to or below MDL (Table S5). For the latter site, a relatively large difference in the estimated uptake rate between the two PAS parallels was also noted (Supplement S1.6).

\section{HCHs}

$\alpha$ - and $\gamma$-HCH were reported for all sites (Fig. 1b,c). The percentage deviation relative to AAS for the $\alpha$ - and $\gamma-\mathrm{HCH}$ isomers ranged from $-43 \%$ (Birkenes) to $+318 \%$ (Stórhöfdi) and from $-48 \%$ (Birkenes) to $+85 \%$ (Košetice) for these two isomers, respectively (Table S5). With the exception of Birkenes, Pallas and Stórhöfdi (latter only for $\gamma-\mathrm{HCH}$ ), positive deviations $\left(\mathrm{C}_{\mathrm{PAS}}>\mathrm{C}_{\mathrm{AAS}}\right)$ were typically observed for these two isomers. For the $\alpha$-HCH isomer, minor deviations were seen for Råö $(+19 \%)$, Spitsbergen $(+23 \%)$ and Pallas $(-17 \%)$. Likewise, good agreement for $\gamma-\mathrm{HCH}$ was found for Stórhöfdi (-8\%), Spitsbergen (+22\%) and Råö (24\%).
Given that the AAS at Stórhöfdi operates on a continuous basis (Table S5) it is difficult to offer an explanation for the large differences seen for $\alpha-\mathrm{HCH}$ at but not for $\gamma-\mathrm{HCH}$ at this site. It is interesting to note that there are significant differences for both $\mathrm{HCHs}$ at Birkenes in spite of both AAS and PAS being analyzed at the same laboratory. Again, a plausible explanation is that differences between AAS and PAS are caused by differences in sampling coverage as the sampling frequency at Birkenes is only one day per week (Table S5).

\section{DDTs}

As several DDTs were either not reported by AAS, or because several results from PAS were found to be below MDL (Table S5, Fig. 1d), a comparison was only possible for Košetice, Råö and Aspvreten. The percentage deviation for $\Sigma_{n}$ DDTs varies from $-34 \%$ (Aspvreten) to $+282 \%$ (Košetice).

\section{PAHs}

For the same reasons as for the DDTs, the comparison for PAHs had to be carried out for a variable number of compounds (phenanthrene, anthracene, fluorathene, pyrene, benzo(a)pyrene, benz(a)anthracene) and limited to four stations (Košetice, Råö, Aspvreten and Pallas), see Fig. 1e. The percentage deviations relative to AAS for $\Sigma_{n}$ PAHs (Table S5) ranged from $+45 \%$ (Råö) to $+216 \%$ (Košetice). The relative deviations for the individual PAHs were mostly positive, except pyrene and benz(a)anthracene at Aspvreten, and benzo(a)pyrene at Košetice. The best agreement between the two air sampling techniques was found for Råö and Pallas $\left(+45 \%\right.$ and $+52 \%$ for $\Sigma_{n}$ PAHs, respectively).

\section{HCB}

Results for HCB obtained on the basis of AAS are only available for Košetice, Birkenes, Spitsbergen and Stórhöfdi (Fig. 1f). For all these sites, except for the latter, the relative deviation was between $+36 \%$ and $-31 \%$ (Table S5). This is in striking contrast to Stórhöfdi for which $\mathrm{C}_{\mathrm{PAS}}$ exceeded $\mathrm{C}_{\mathrm{AAS}}$ by as much as $+1540 \%$. Hung et al. (2010) recently pointed out that all Arctic monitoring stations showed similar air concentrations after year 2000 with annual average air HCB concentrations between 29 and $76 \mathrm{pg} \mathrm{m}^{-3}$, while Stórhöfdi had much lower concentrations (2 to $6.8 \mathrm{pg} \mathrm{m}^{-3}$ ). As the PAS results for the other sites compare favourably with AAS results, the large discrepancy for HCB at Stórhöfdi merits further investigation. This example also illustrates how coordinated PAS campaigns has the potential to serve as an inter-comparison exercise within and across existing monitoring programs, which could complement other relevant efforts, e.g. inter laboratory comparisons. 

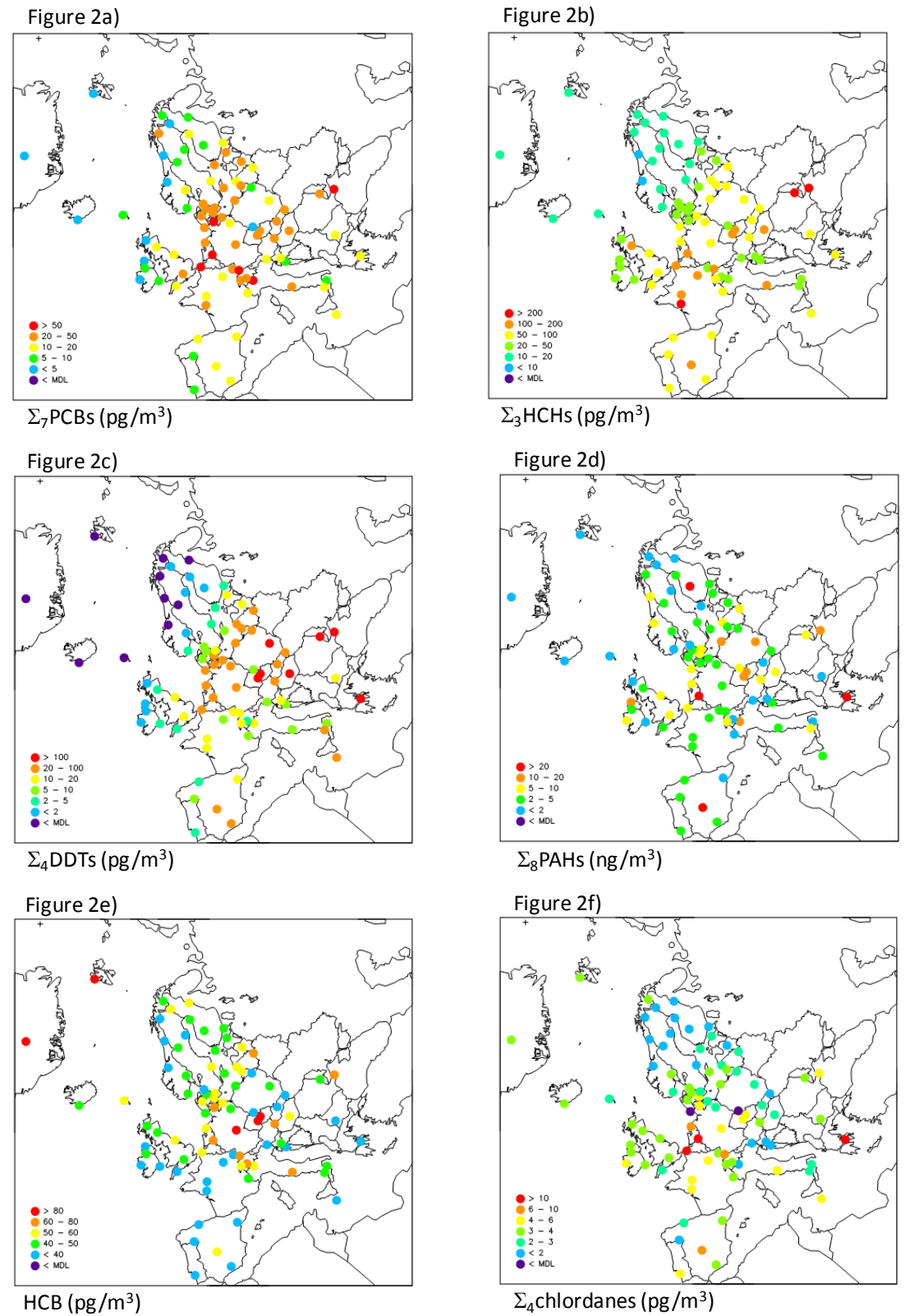

Fig. 2. (a)-(f): Spatial patterns of $\Sigma_{7}$ PCBs, $\Sigma_{3} \mathrm{HCHs}, \Sigma_{4}$ DDTs, $\Sigma_{8}$ PAHs, HCB and $\Sigma_{4}$ chlordanes in European background air.

\subsection{Spatial patterns}

As most EMEP monitoring stations reporting POPs in air are mainly located in the northwestern part of Europe (Aas and Breivik, 2008), an additional objective of this study was to evaluate potential limitations in the current EMEP measurement network with respect to spatial coverage. Improved spatial coverage is not only considered important to support relevant modelling activities within EMEP (e.g. Malanichev et al., 2004) and beyond, but it may also provide useful information for future monitoring strategies within EMEP.

\section{PCBs}

Figure 2a shows the results for $\Sigma_{7} \mathrm{PCBs}$ while Fig. S3a-g presents the spatial patterns of individual PCB congeners across Europe. Similar to past studies, elevated levels of PCBs were typically found in more densely populated areas in central parts of Europe (Jaward et al., 2004a). Lower levels of PCBs tended to occur along the western coast of Scandinavia, the British Isles and to some extent Spain/Portugal, which may be explained by the prevailing wind regimes with transport from west to east. Elevated levels of $\Sigma_{7}$ PCBs 
$\left(>50 \mathrm{pg} \mathrm{m}^{-3}\right)$ were detected at sites in Belgium, Germany, Italy, the Netherland and Ukraine, while the highest concentrations were observed at a site in Denmark $\left(121 \mathrm{pg} \mathrm{m}^{-3}\right)$. Whenever significantly elevated levels are measured at a specific site, this may indicate an influence from one or more nearby sources as may be the case with the elevated levels seen at the Danish site.

\section{HCHs}

The spatial patterns for $\Sigma_{3} \mathrm{HCHs}$ and individual $\mathrm{HCHs}$ across Europe are shown in Fig. 2b) and Fig. S4(a-c), respectively. HCHs are insecticides which have been extensively used in Europe (Breivik et al., 1999) and the rest of the world (e.g. Li et al., 1996, 1999). The results for $\Sigma_{3} \mathrm{HCHs}$ shows a fairly consistent pattern with low levels $\left(<20 \mathrm{pg} \mathrm{m}^{-3}\right)$ at most Scandinavian and Arctic sites. Elevated levels $\left(>200 \mathrm{pg} \mathrm{m}^{-3}\right)$ were recorded at certain sites in France, Moldova and Ukraine. HCHs ultimately originate from the production and use of technical $\mathrm{HCH}(55-80 \% \alpha-$ $\mathrm{HCH}, 2-16 \% \beta-\mathrm{HCH}, 8-15 \% \gamma-\mathrm{HCH})$ or lindane $(>99 \% \gamma-$ $\mathrm{HCH}$ (Breivik et al., 1999). Hence, while the occurrence of $\gamma-\mathrm{HCH}$ may be attributed to either technical $\mathrm{HCH}$ or lindane, $\alpha$ - and $\beta$-HCH were only major constituents in the technical mixture. In general terms, lindane usage tended to dominate in the western part of Europe, while technical HCH tended to dominate in the eastern part (Breivik et al., 1999). This pattern is also reflected in the results, whereby elevated levels of $\alpha$ - and $\beta$-HCH are mainly seen at some sites in the southeastern areas of Europe (Fig. S4a,b). As $\beta$-HCH is more easily washed out by rain than $\alpha-\mathrm{HCH}$, elevated atmospheric concentrations of $\beta-\mathrm{HCH}$ may hence be a more useful indicator to identify proximity to regions or areas that are affected by ongoing or past historical usage of technical $\mathrm{HCH}$. Elevated levels of $\gamma-\mathrm{HCH}$ tend to occur across central parts of Europe (Fig. S4c). Given the remoteness from key source areas, relatively high levels of $\alpha-\mathrm{HCH}$ are also observed at the sites in Iceland, Greenland and Spitsbergen, which may be seen as a reflection of the elevated long-range atmospheric transport potential of this isomer ( $\mathrm{Li}$ et al., 2002; Wania and Mackay, 1996; Beyer et al., 2000).

\section{DDTs}

The spatial patterns of $\Sigma_{4}$ DDTs and individual DDTs are presented in Fig. 2c and Fig. S5a-d), respectively. The technical mixture of DDT contains up to $80-85 \%$ of the $p, p^{\prime}-\mathrm{DDT}$ isomer and only small amounts of the $o, p^{\prime}$-DDT isomer (15-20\%) (Motelay-Massei et al., 2005) and was banned in European countries during the 1970s and 1980s (Pacyna et al., 2003). Levels of $\Sigma_{4}$ DDTs were generally low and frequently below the MDL in Northern Europe but with increasing air concentrations towards Central and Eastern Europe (Fig. 2c). Concentrations of
$\Sigma_{4}$ DDTs above $100 \mathrm{pg} \mathrm{m}^{-3}$ occurred at sites in the Czech Republic, Greece, Hungary, Moldova, Poland and Ukraine (Fig. 2c). The spatial pattern for individual isomers (Fig. S5) generally reflected that of $\Sigma_{4}$ DDTs, although absolute air concentrations varied. A $p, p^{\prime}-\mathrm{DDE} / p, p^{\prime}-\mathrm{DDT}$ ratio lower than 1 has been proposed as an indication of fresh use of technical DDT (Pozo et al., 2006). This ratio is shown in Fig. S5e). Jaward (2004a) previously noted low $p, p^{\prime}-\mathrm{DDE} / p, p^{\prime}-\mathrm{DDT}$ ratios in European air, which suggest a fresh $p, p^{\prime}-$ DDT signal. This is in contrast to our results four years later, which indicates a more weathered signal with an average ratio of 3.8 (range 0.9-8.5) (Fig. S5e). A ratio higher than 1 is also in better accordance with observations based on AAS from various EMEP sites (Košetice, Pallas, Stórhöfdi, Spitsbergen and Råö) which show a mean value for this ratio in the range between 1.3 and 10.9 during 2006 (Aas and Breivik, 2008). The ratio $o, p^{\prime}-\mathrm{DDT} / p, p^{\prime}-\mathrm{DDT}$ (Fig. S5f) has previously been used to evaluate possible influence from dicofol, a miticide which contains $10 \%$ of the $o, p^{\prime}-\mathrm{DDT}$ isomer (Becker, 2008; Gillespie et al., 1994; Qiu et al., 2005). Several countries in Europe (e.g. Italy, United Kingdom, Spain and Turkey) utilize dicofol in agriculture (Gillespie et al., 1994; Turgut et al., 2009). This study confirms several sites which had higher values for the $o, p^{\prime}-$ DDT isomer in comparison to the $p, p^{\prime}-\mathrm{DDT}$ isomer. The average ratio $( \pm \mathrm{SD})$ was $0.86 \pm 0.26$ and spanned from $0.3-1.6$ which may suggest some influence from dicofol at certain sites. A ratio higher than 1 was found at sites in Austria, Denmark, Finland, France, Ireland, Italy, Kazakhstan, Lithuania, Moldova, the Netherlands, Norway, Poland, Sweden and United Kingdom (Fig. S5f).

\section{PAHs}

Figure $2 \mathrm{~d}$ shows the spatial pattern for $\Sigma_{8} \mathrm{PAHs}$ across Europe (see also Fig. S6). PAHs are by-products from incomplete combustion processes with many different sources (Lohmann et al., 2000). No clear trend in spatial patterns could be found, and it seems likely that the sites which are experiencing elevated concentrations are mainly affected by local sources. Hence, many of the sites included may not be considered true background sites with respect to PAHs. Elevated concentrations of $\Sigma_{8}$ PAHs $\left(>20 \mathrm{ng} \mathrm{m}^{-3}\right)$ where observed at sites in Finland, Greece, the Netherlands and Spain (Fig. 2d).

\section{HCB}

The spatial pattern for HCB is presented in Fig. 2e. HCB is highly volatile, persistent in air and expected to be extensively re-emitted from secondary sources like soil and vegetation (Bailey, 2001; Barber et al., 2005). As previously recognized in this study (Table 1) and elsewhere (Jaward et 
al., 2004a) concentrations are relatively uniform across Europe. Elevated air concentrations $\left(>100 \mathrm{pg} \mathrm{m}^{-3}\right)$ occurred at four sites, two of which are found at high elevation (Summit, Spitsbergen). Yet, as the uptake rate for these two sites rely on the default value, we suspect air concentrations may have been overestimated as the true uptake rates at these exposed sites may have been underestimated due to wind speed effects (Tuduri et al., 2006).

\section{Chlordanes}

The spatial pattern for $\Sigma_{4}$ chlordanes is presented in Fig. 2f), and for individual compounds in Fig. S7. The technical mixture of chlordane consists mainly of trans-chlordane, cis-chlordane and trans-nonachlor (Sovocool et al., 1977; Dearth and Hites, 1990). Chlordane were formerly used in agriculture as an insecticide and termiticide up to the mid 1980s (Bidleman et al., 2002). The levels of the individual chlordanes were typically low and several sites were below MDL. The predominating compounds were trans-chlordane and trans-nonachlor, while cis-nonachlor were found at lowest levels. Elevated levels of $\Sigma_{4}$ chlordanes $\left(>10 \mathrm{pg} \mathrm{m}^{-3}\right)$ were found at sites in Belgium, Greece and the Netherlands. The trans-chlordane/cis-chlordane (TC/CC) ratio is 1.56 in the technical chlordane mixture (Bidleman et al., 2002). trans-chlordane is more easily degraded than cischlordane in the environment and ratio values for TC/CC close to 1 implies a weathered signal. Consequently elevated ratios may indicate fresh usage of technical chlordane (Pozo et al., 2004). The average ratio $( \pm \mathrm{SD})$ was $0.5 \pm 0.4$ and spanned from $0.03-2.6$. Sites with a ratio $>1.56$ were found in Moldova (1.57), the Netherlands $(1.61,1.63)$ and Malta (2.58).

\subsection{Model evaluations}

The atmospheric transport model FLEXPART was used in a time-reverse mode to identify the source regions responsible for the PCB-28 loading at the respective sampling site in addition the meteorological parameters driving the transport. In contrast to classical trajectory calculations (Gouin et al., 2005a) turbulence, convection and removal processes (dry and wet deposition, reaction with $\mathrm{OH}$ ) are taken into account. In this manner the source regions for each sample can be identified and an emission sensitivity (ES) map can be derived. Combining this information with the PCB-28 emission inventory (Breivik et al., 2007) a concentration for each receptor can be predicted, resulting in a emission contribution (EC) map. We selected PCB-28 to illustrate the model approach as (a) unlike several compounds included in this study, PCB-28 exists solely in the gaseous state in the atmosphere, and (b) a spatially resolved emission inventory is available which is essential as model input. The model was run for 17 of the sites included in this study, including all

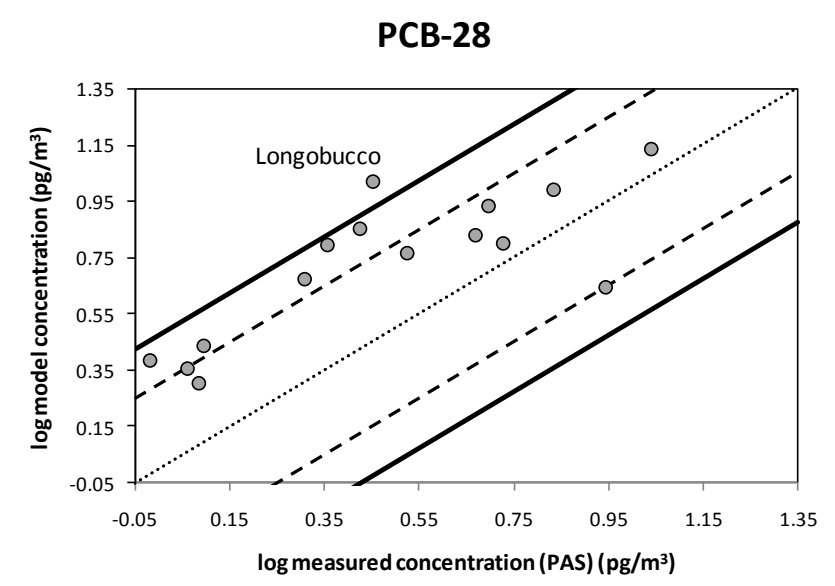

Fig. 3. Modelled versus observed (PAS) air concentrations for PCB28 at selected sites. The dashed and solid lines represent agreement within a factor of 2 and 3 , respectively.

EMEP AAS to also facilitate a comparison between model and measurements derived using on the basis of both AAS and PAS. Table S6 presents the sites along with predicted and observed concentrations, including percentage deviation between model and PAS measurement results, while Fig. 3 shows the modelled versus observed air concentrations, both expressed on a logarithmic basis. The agreement between PAS and model results were found to be within a factor of 3 for 16 out of 17 sites (solid black lines), with most results within a factor of 2 (dashed lines). It is possible that the overestimation of the model is caused by too high emissions in the inventory. The overall results also show that the model predicted values in comparison to AAS results which were 2-3 times higher at four out of seven sites (Košetice, Birkenes, Råö, Aspvreten) and 2-12 times lower for the other sites (Pallas, Stórhöfdi, Spitsbergen) (Table S6).

The results for PCB-28 also allow us to explore whether it is likely that the air masses sampled by PAS and AAS differed during the campaign and hence could have led to some of the discrepancies observed (Fig. 1 and Table S5). This was explored for the two sites where sampling coverage were most different (Košetice and Birkenes) by averaging the model predicted air concentration corresponding to the AAS sampling times at each of the sites. While the average PAS concentration at Košetice was $69 \%$ higher than the air concentration derived on the basis of AAS, the average PAS concentration at Birkenes was $4 \%$ lower than results obtained on the basis of AAS (Table S5). Contrary to what would be expected if differences in air masses sampled would be the main reason for difference noted (Table S5), the model results for Košetice corresponding to the AAS sampling period alone was $93 \%\left(12.6 \mathrm{pg} \mathrm{m}^{-3}\right)$ compared with the air concentration derived over the entire PAS sampling period (Table S6). Similarly, air concentrations at Birkenes for the AAS sampling period alone represented only $64 \%$ 

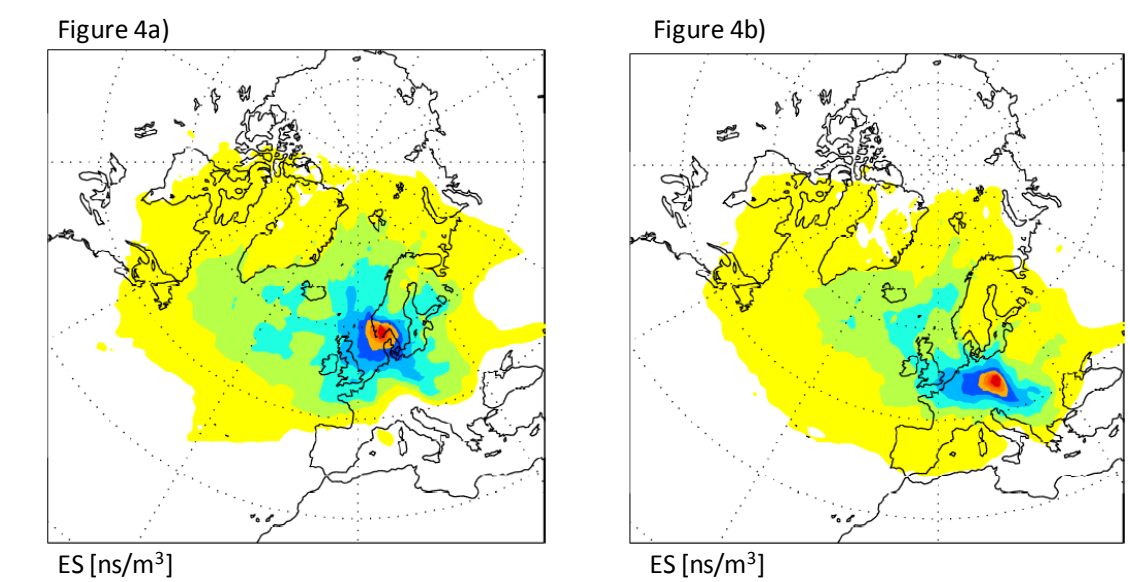

$\mathrm{ES}\left[\mathrm{ns} / \mathrm{m}^{3}\right]$

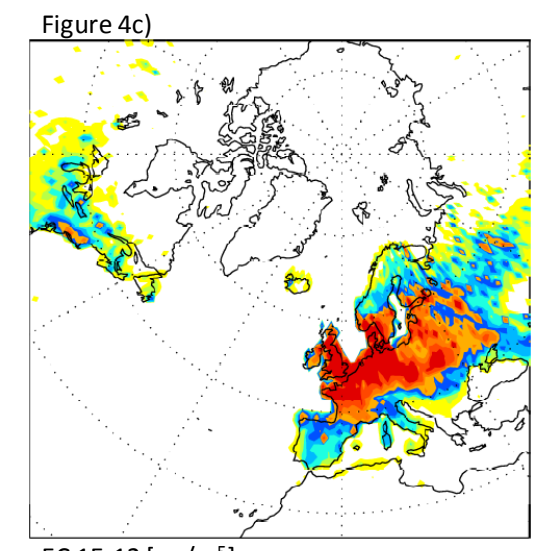

EC $1 \mathrm{E}-12\left[\mathrm{pg} / \mathrm{m}^{5}\right]$

\section{Figure 4d)}

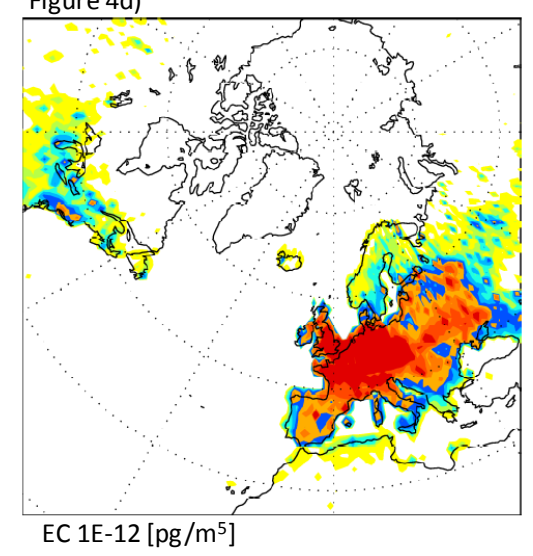

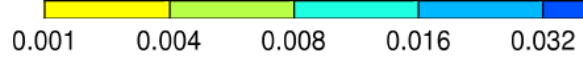

0.064

0.125

0.25

0.5

Fig. 4. (a-d): Maps of Footprint ES (emission sensitivity) (a), (b) and EC (emission contribution) (c), (d) for PCB-28 for the PAS sampling period at Birkenes (a), (c) and Košetice (b), (d) (see text for details).

$\left(2.98 \mathrm{pg} \mathrm{m}^{-3}\right)$ of the average air concentration derived for the PAS deployment period. For Košetice it thus seems likely that some of the discrepancy may be better explained by other factors, such as a tendency for the model to overestimate air concentrations as noted above and/or due to interlaboratory differences. The latter explanation cannot be the reason for Birkenes as both AAS and PAS were analyzed at the same laboratory.

In a recent study by Eckhardt et al. (2009) the same method was used in order to identify source regions contributing to the loadings of PCB-28 at the Birkenes site (for sampling times of $24 \mathrm{~h}$ ). Again, Košetice and Birkenes (Fig. 4), where chosen for further discussion of the model results, while additional model results can be found in the Supplement (Figs. S8 to S22). As the air masses controlling observed air concentrations are expected to differ between PAS and AAS results, we have additionally included results representing AAS sampling times alone for the Košetice and Birkenes sites in Figs. S23-S24. Yet, these results were rather similar to the results obtained for the entire PAS campaign (Fig. 4) and are thus not discussed any further. The ES maps in Fig. 4a,b) shows the residence time of the air masses in the so called the footprint layer $(0-100 \mathrm{~m}$ a.g.l. $)$ where potential uptake of emissions can take place. Looking at the source regions of the air masses influencing the two sites (upper row) it can be seen for both that the local influence gives the greatest contribution and the prevailing westerly winds extend the source region towards North America. Air masses flow in both cases over the British Isles. For Košetice, also Southern and Eastern Europe is an important influence. This can be seen when looking at the EC-maps (Fig. 4c,d), where emission fluxes (Breivik et al., 2007) are incorporated. Integrating over the maps shown in the lower row of Fig. 4 yields an estimated concentration of $4.7 \mathrm{pg} \mathrm{m}^{-3}$ and $13.6 \mathrm{pg} \mathrm{m}^{-3}$ for Birkenes and Košetice respectively (Table S6). The influence of Southern and Eastern Europe is larger for Košetice than for Birkenes. We caution, however, that these model results rest on the critical assumption that air concentrations 
of PCB-28 are controlled by primary emissions alone. This assumption may be criticized as it is well established that PCBs have the potential to undergo reversible atmospheric deposition. For example, soils have a large capacity to retain PCBs (Meijer et al., 2003) and several recent studies have indicated that lower molecular weight PCBs may be subject to significant re-volatilization from urban and industrial soils, following reductions in primary emissions ( $\mathrm{Li}$ et al., 2010; Ruzickova et al., 2008). At the same time, Li et al. (2010) also conclude that air concentrations at remote and background sites were mostly influenced by primary sources, which is both in agreement with long-term time trends of PCBs in European background air (Schuster et al., 2010) and in line with the model assumptions made herein.

\section{Conclusions}

This study presents new data on the spatial pattern of selected POPs in European background air. As illustrated for PCB-28, these data are expected to be of significant value for future attempts to evaluate relevant atmospheric fate and transport models for Europe, both within EMEP and beyond. The results combined further illustrates that PAS may complement future monitoring strategies within the EMEP program. The observed spatial variability of POPs in air also highlighted limitations of the current EMEP measurement network with respect to spatial coverage. Finally, we conclude that coordinated PAS campaigns may have the potential to serve as useful inter-comparison exercises within and across existing monitoring networks which could complement interlaboratory comparison studies.

\section{Supplementary material related to this article is available online at: http://www.atmos-chem-phys.net/11/1549/2011/ acp-11-1549-2011-supplement.zip.}

Acknowledgements. The authors thank Tom Harner, Eva Brorström-Lundén, and Ivan Holoubek for advice and colleagues at NILU (S. Manø, A. Borgen, H. Gundersen, M. Ghebremeskel, A. G. Hjellbrekke and S. E. Walker) for support. We would also like to thank the volunteers within and outside the European Monitoring and Evaluation Programme (EMEP) for their valuable assistance in the field. Isabel Bey has provided the $\mathrm{OH}$ fields and the Norwegian MetOffice have given us access to the ECMWF data. This study received financial support from the Research Council of Norway (183437/S30), EMEP and the Nordic Council of Ministers. Lancaster University acknowledge financial support from the UK Department of Food and Rural Affairs for research and monitoring work on persistent organic pollutants.

Edited by: H. C. Hansson

\section{References}

Aas, W. and Breivik, K.: Heavy metals and POPs measurements, 2006 Co-operative programme for monitoring and evaluation of long range transmission of air pollutants in Europe (EMEP), NILU, Kjeller, 2008.

Aas, W. and Breivik, K.: Heavy metals and POP measurements 2007, Co-operative programm for monitoring and evaluation of long-range transmissions of air pollutants in Europe, NILU, KjellerO-95038/O-99050, 3-117, 2009.

Bailey, R. E.: Global hexachlorobenzene emissions, Chemosphere, 43, 167-182, 2001.

Barber, J. L., Sweetman, A. J., van Wijk, D., and Jones, K. C.: Hexachlorobenzene in the global environment: Emissions, levels, distribution, trends and processes, Sci. Total Environ., 349, 1-44, doi:10.1016/j.sciotenv.2005.03.014, 2005.

Bartkow, M. E., Jones, K. C., Kennedy, K. E., Holling, N., Hawker, D. W., and Müller, J. F.: Evaluation of performance reference compounds in polyethylene-based passive air samplers, Environ. Pollut., 144, 365-370, doi:10.1016/j.envpol.2005.12.043, 2006 .

Bartkow, M. E., Kennedy, K. E., Huckins, J. N., Holling, N., Komarova, T., and Müller, J. F.: Photodegradation of polyaromatic hydrocarbons in passive air samplers: Field testing different deployment chambers, Environ. Pollut., 144, 371-376, doi:10.1016/j.envpol.2005.12.050, $2006 \mathrm{~b}$.

Becker, S.: Trends and behaviour of semi-volatile organic compounds in the Artic Atmosphere, Ph.D., Environmental Science Department, Lancaster University, Lancaster, UK, 2008.

Beyer, A., Mackay, D., Matthies, M., Wania, F., and Webster, E.: Assessing long-range transport potential of persistent organic pollutants, Environ. Sci. Technol., 34, 699-703, 2000.

Bidleman, T. F., Jantunen, L. M. M., Helm, P. A., BrorstromLunden, E., and Juntto, S.: Chlordane enantiomers and temporal trends of chlordane isomers in arctic air, Environ. Sci. Technol., 36, 539-544, doi:10.1021/es011142b, 2002.

Breivik, K. and Wania, F.: Mass budgets, pathways, and equilibrium states of two hexachlorocyclohexanes in the Baltic Sea environment, Environ. Sci. Technol., 36, 1024-1032, doi:10.1021/es001972+, 2002.

Breivik, K., Pacyna, J. M., and Munch, J.: Use of alpha-, betaand gamma-hexachlorocyclohexane in Europe, 1970-1996, Sci Total. Environ., 239, 151-163, 1999.

Breivik, K., Sweetman, A., Pacyna, J. M., and Jones, K. C.: Towards a global historical emission inventory for selected PCB congeners - A mass balance approach-3. An update, Sci. Total Environ., 377, 296-307, doi:10.1016/j.scitotenv.2007.02.026, 2007.

Chaemfa, C., Barber, J. L., Gocht, T., Harner, T., Holoubek, I., Klanova, J., and Jones, K. C.: Field calibration of polyurethane foam (PUF) disk passive air samplers for PCBs and OC pesticides, Environ. Pollut., 156, 1290-1297, doi:10.1016/j.envpol.2008.03.016, 2008.

Chaemfa, C., Barber, J. L., Kim, K. S., Harner, T., and Jones, K. C.: Further studies on the uptake of persistent organic pollutants (POPs) by polyurethane foam disk passive air samplers, Atmos. Environ., 43, 3843-3849, doi:10.1016/j.atmosenv.2009.05.020, 2009a.

Chaemfa, C., Wild, E., Davison, B., Barber, J. L., and Jones, K. C.: A study of aerosol entrapment and the influence of wind speed, chamber design and foam density on polyurethane foam passive 
air samplers used for persistent organic pollutants, J. Environ. Monit., 11, 1135-1139, doi:10.1039/b823016a, 2009b.

Dearth, M. A. and Hites, R. A.: Highly chlorinated dimethanofluorenes in technical chlordane and in human adipose-tissue, J. Am. Soc. Mass. Spectr., 1, 99-103, 1990.

Eckhardt, S., Breivik, K., Li, Y. F., Manø, S., and Stohl, A.: Source regions of some persistent organic pollutants measured in the atmosphere at Birkenes, Norway, Atmos. Chem. Phys., 9, 65976610, doi:10.5194/acp-9-6597-2009, 2009.

Gillespie, M. J., Lythgo, C. M., Plumb, A. D., and Wilkins, J. P. G.: A survey comparing the chemical composition of dicofol formulations sold in the UK before and after the introduction of the EC prohibition directive 79/117/EEC, Pestic. Sci., 42, 305-314, 1994.

Gouin, T., Harner, T., Blanchard, P., and Mackay, D.: Passive and active air samplers as complementary methods for investigating persistent organic pollutants in the Great Lakes basin, Environ. Sci. Technol., 39, 9115-9122, doi:10.1021/ES051387f, 2005a.

Gouin, T., Harner, T., Daly, G. L., Wania, F., Mackay, D., and Jones, K. C.: Variability of concentrations of polybrominated diphenyl ethers and polychlorinated biphenyls in air: implications for monitoring, modeling and control, Atmos. Environ., 39, 151-166, doi:10.1016/j.atmosenv.2004.09.022, 2005 b.

Gouin, T., Wania, F., Ruepert, C., and Castillo, L. E.: Field testing passive air samplers for current use pesticides in a tropical environment, Environ. Sci. Technol., 42, 6625-6630, doi:10.1021/es8008425, 2008.

Halsall, C. J., Coleman, P. J., Davis, B. J., Burnett, V., Waterhouse, K. S., Hardingjones, P., and Jones, K. C.: Polycyclic aromatichydrocarbons in UK urban air, Environ. Sci. Technol., 28, 23802386, 1994.

Harju, M., Haglund, P., and Naikwadi, K., P: Gas-chromatographic properties of the 209 PCB congeners on non-polar, chiral and liquid-crystal columns, Organohalogen compounds, 35, 111114, 1998.

Harner, T. and Bidleman, T. F: Measurement of octanol-air partition coefficients for polychlorinated biphenyls, J. Chem. Eng. Data, 41, 895-899, 1996.

Harner, T., Shoeib, M., Diamond, M., Stern, G., and Rosenberg, B.: Using passive air samplers to assess urban - Rural trends for persistent organic pollutants. 1. Polychlorinated biphenyls and organochlorine pesticides, Environ. Sci. Technol., 38, 44744483, doi:10.1021/es040302r, 2004.

Harner, T., Bartkow, M., Holoubek, I., Klanova, J., Wania, F., Gioia, R., Moeckel, C., Sweetman, A. J., and Jones, K. C.: Passive air sampling for persistent organic pollutants: Introductory remarks to the special issue, Environ. Pollut., 144, 361-364, doi:10.1016/j.envpol.2005.12.044, 2006a.

Harner, T., Pozo, K., Gouin, T., Macdonald, A. M., Hung, H., Cainey, J., and Peters, A.: Global pilot study for persistent organic pollutants (POPs) using PUF disk passive air samplers, Environ. Pollut., 144, 445-452, doi:10.1016/j.envpol.2005.12.053, 2006b.

Harner, T., Shoeib, M., Diamond, M., Ikonomou, M., and Stern, G.: Passive sampler derived air concentrations of PBDEs along an urban-rural transect: Spatial and temporal trends, Chemosphere, 64, 262-267, doi:10.1016/j.chemosphere.2005.12.018, $2006 \mathrm{c}$.

Hayward, S. J., Gouin, T., and Wania, F.: Comparison of Four Active and Passive Sampling Techniques for Pesticides in Air,
Environ. Sci. Technol., 44, 3410-3416, doi:10.1021/es902512h, 2010.

Huckins, J. N., Petty, J. D., Lebo, J. A., Almeida, F. V., Booij, K., Alvarez, D. A., Clark, R. C., and Mogensen, B. B.: Development of the permeability/performance reference compound approach for in situ calibration of semipermeable membrane devices, Environ. Sci. Technol., 36, 85-91, doi:10.1021/es010991w, 2002.

Hung, H., Kallenborn, R., Breivik, K., Su, Y., Brorström-Lundén, E., Olafsdottir, K., Thorlacius, J. M., Leppänen, S., Bossi, R., Skov, H., Man $\varnothing$, S., Patton, G. W., Stern, G., Sverko, E., and Fellin, P.: Atmospheric monitoring of organic pollutants in the Arctic under the Arctic Monitoring and Assessment Programme (AMAP): 1993-2006, Sci. Total Environ., in press, Corrected Proof, doi:10.1016, 2010.

Jaward, F. M., Farrar, N. J., Harner, T., Sweetman, A. J., and Jones, K. C.: Passive air sampling of PCBs, PBDEs, and organochlorine pesticides across Europe, Environ. Sci. Technol., 38, 34-41, doi:10.1021/es034705n, 2004a.

Jaward, F. M., Farrar, N. J., Harner, T., Sweetman, A. J., and Jones, K. C.: Passive air sampling of polycyclic aromatic hydrocarbons and polychlorinated naphthalenes across Europe, Environ. Toxicol. Chem., 23, 1355-1364, 2004b.

Jaward, T. M., Zhang, G., Nam, J. J., Sweetman, A. J., Obbard, J. P., Kobara, Y., and Jones, K. C.: Passive air sampling of polychlorinated biphenyls, organochlorine compounds, and polybrominated diphenyl ethers across Asia, Environ. Sci. Technol., 39, 8638-8645, doi:10.1021/es051382h, 2005.

Kennedy, K., Hawker, D. W., Bartkow, M. E., Carter, S., Ishikawa, Y., and Mueller, J. F.: The potential effect of differential ambient and deployment chamber temperatures on PRC derived sampling rates with polyurethane foam (PUF) passive air samplers, Environ. Pollut., 158, 142-147, doi:10.1016/j.envpol.2009.07.031, 2010.

Klanova, J., Eupr, P., Kohoutek, J., and Harner, T.: Assessing the influence of meteorological parameters on the performance of polyurethane foam-based passive air samplers, Environ. Sci. Technol., 42, 550-555, doi:10.1021/es072098o, 2008.

Li, N. Q., Wania, F., Lei, Y. D., and Daly, G. L.: A comprehensive and critical compilation, evaluation, and selection of physicalchemical property data for selected polychlorinated biphenyls, J. Phys. Chem. Ref. Data., 32, 1545-1590, doi:10.1063/1.1562632, 2003.

Li, Y. F.: Global technical hexachlorocyclohexane usage and its contamination consequences in the environment: from 1948 to 1997, Sci. Total. Environ., 232, 121-158, 1999.

Li, Y. F., McMillan, A., and Scholtz, M. T.: Global HCH usage with 1 degrees $\mathrm{x} 1$ degrees longitude/latitude resolution, Environ. Sci. Technol., 30, 3525-3533, 1996.

Li, Y. F., Macdonald, R. W., Jantunen, L. M. M., Harner, T., Bidleman, T. F., and Strachan, W. M. J.: The transport of betahexachlorocyclohexane to the western Arctic Ocean: a contrast to alpha-HCH, Sci. Total Environ., 291, 229-246, 2002.

Li, Y. F., Harner, T., Liu, L. Y., Zhang, Z., Ren, N. Q., Jia, H. L., Ma, J. M., and Sverko, E.: Polychlorinated Biphenyls in Global Air and Surface Soil: Distributions, Air-Soil Exchange, and Fractionation Effect, Environ. Sci. Technol., 44, 2784-2790, doi:10.1021/es901871e, 2010.

List of signatories and ratifications to the Stockholm Convention on POPs: http://www.pops.int/documents/signature/signstatus.htm, 
2003.

Lohmann, R., Northcott, G. L., and Jones, K. C.: Assessing the contribution of diffuse domestic burning as a source of PCDD/Fs, PCBs, and PAHs to the UK atmosphere, Environ. Sci. Technol., 34, 2892-2899, doi:10.1021/es991183w, 2000.

Malanichev, A., Mantseva, E., Shatalov, V., Strukov, B., and Vulykh, N.: Numerical evaluation of the PCBs transport over the Northern Hemisphere, Environ. Pollut., 128, 279-289, doi:10.1016/j.envpol.2003.08.040, 2004.

Mari, M., Schuhmacher, M., Feliubadalo, J., and Domingo, J. L.: Air concentrations of PCDD/Fs, PCBs and PCNs using active and passive air samplers, Chemosphere, 70, 1637-1643, doi:10.1016/j.chemosphere.2007.07.076, 2008.

Meijer, S. N., Ockenden, W. A., Sweetman, A., Breivik, K., Grimalt, J. O., and Jones, K. C.: Global distribution and budget of PCBs and HCB in background surface soils: Implications or sources and environmental processes, Environ. Sci. Technol., 37, 667-672, doi:10.1021/es0258091, 2003.

Moeckel, C., Harner, T., Nizzetto, L., Strandberg, B., Lindroth, A., and Jones, K. C.: Use of Depuration Compounds in Passive Air Samplers: Results from Active Sampling-Supported Field Deployment, Potential Uses, and Recommendations, Environ. Sci. Technol., 43, 3227-3232, doi:10.1021/es802897x, 2009.

Motelay-Massei, A., Harner, T., Shoeib, M., Diamond, M., Stern, G., and Rosenberg, B.: Using passive air samplers to assess urban-rural trends for persistent organic pollutants and polycyclic aromatic hydrocarbons. 2. Seasonal trends for PAHs, PCBs, and organochlorine pesticides, Environ. Sci. Technol., 39, 5763-5773, doi:10.1021/es0504183, 2005.

Pacyna, J. M., Breivik, K., Munch, J., and Fudala, J.: European atmospheric emissions of selected persistent organic pollutants, 1970-1995, S119-S131, 2003.

Pozo, K., Harner, T., Shoeib, M., Urrutia, R., Barra, R., Parra, O., and Focardi, S.: Passive-sampler derived air concentrations of persistent organic pollutants on a north-south transect in Chile, Environ. Sci. Technol., 38, 6529-6537, doi:10.1021/es049065i, 2004.

Pozo, K., Harner, T., Wania, F., Muir, D. C. G., Jones, K. C., and Barrie, L. A.: Toward a global network for persistent organic pollutants in air: Results from the GAPS study, Environ. Sci. Technol., 40, 4867-4873, doi:10.1021/es060447t, 2006.

Pozo, K., Harner, T., Lee, S. C., Wania, F., Muir, D. C. G., and Jones, K. C.: Seasonally Resolved Concentrations of Persistent Organic Pollutants in the Global Atmosphere from the First Year of the GAPS Study, Environ. Sci. Technol., 43, 796-803, doi:10.1021/es802106a, 2009.

Qiu, X. H., Zhu, T., Yao, B., Hu, J. X., and Hu, S. W.: Contribution of dicofol to the current DDT pollution in China, Environ. Sci. Technol., 39, 4385-4390, doi:10.1021/es050342a, 2005.

Ruzickova, P., Klanova, J., Cupr, P., Lammel, G., and Holoubek, I.: An assessment of air-soil exchange of polychlorinated biphenyls and organochlorine pesticides across Central and Southern Europe, Environ. Sci. Technol., 42, 179-185, doi:10.1021/es071406f, 2008.

Santiago, E. C. and Cayetano, M. G.: Polycyclic aromatic hydrocarbons in ambient air in the Philippines derived from passive sampler with polyurethane foam disk, Atmos. Environ., 41, 41384147, doi:10.1016/j.atmosenv.2007.01.021, 2007.

Schuster, J. K., Gioia, R., Breivik, K., Steinnes, E., Scheringer, M., and Jones, K. C.: Trends in European Background Air Reflect Reductions in Primary Emissions of PCBs and PBDEs, Environ. Sci. Technol., 44, 6760-6766, doi:10.1021/es101009x, 2010.

Seibert, P. and Frank, A.: Source-receptor matrix calculation with a Lagrangian particle dispersion model in backward mode, Atmos. Chem. Phys., 4, 51-63, doi:10.5194/acp-4-51-2004, 2004.

Shoeib, M. and Harner, T.: Using measured octanol-air partition coefficients to explain environmental partitioning of organochlorine pesticides, 21, 984-990, 2002a.

Shoeib, M. and Harner, T.: Characterization and comparison of three passive air samplers for persistent organic pollutants, Environ. Sci. Technol., 36, 4142-4151, doi:10.1021/es020635t, $2002 b$.

Sovocool, G. W., Lewis, R. G., Harless, R. L., Wilson, N. K., and Zehr, R. D.: Analysis of technical chlordane by gas chromatography mass spectrometry., Anal. Chem., 49, 734-740, 1977.

Stohl, A., Hittenberger, M., and Wotawa, G.: Validation of the Lagrangian particle dispersion model FLEXPART against largescale tracer experiment data, Atmos. Environ., 32, 4245-4264, 1998.

Stohl, A. and Thomson, D. J.: A density correction for Lagrangian particle dispersion models, Bound.-Lay. Meteorol., 90, 155-167, 1999.

Stohl, A., Forster, C., Eckhardt, S., Spichtinger, N., Huntrieser, H., Heland, J., Schlager, H., Wilhelm, S., Arnold, F., and Cooper, O.: A backward modeling study of intercontinental pollution transport using aircraft measurements, J. Geophys. Res.-Atmos., 108(18), 4370, doi:10.1029/2002jd002862, 2003.

Stohl, A., Forster, C., Frank, A., Seibert, P., and Wotawa, G.: Technical note: The Lagrangian particle dispersion model FLEXPART version 6.2, Atmos. Chem. Phys., 5, 2461-2474, doi:10.5194/acp-5-2461-2005, 2005.

Su, Y. S. and Hung, H. L.: Inter-laboratory comparison study on measuring semi-volatile organic chemicals in standards and air samples, Environ. Pollut., 158, 3365-3371, doi:10.1016/j.envpol.2010.07.041, 2010.

Tuduri, L., Harner, T., and Hung, H.: Polyurethane foam (PUF) disks passive air samplers: Wind effect on sampling rates, Environ. Pollut., 144, 377-383, doi:10.1016/j.envpol.2005.12.047, 2006.

Turgut, C., Gokbulut, C., and Cutright, T. J.: Contents and sources of DDT impurities in dicofol formulations in Turkey, Environ. Sci. Pollut. R., 16, 214-217, doi:10.1007/s11356-008-0083-3, 2009.

The 1998 Aarhus Protocol on persistant organic pollutants (POPs): United Nations Economics Commission for Europe: http://www. unece.org/env/lrtap/welcome.html, 1998.

Vallack, H. W., Bakker, D. J., Brandt, I., Brostrom-Lunden, E., Brouwer, A., Bull, K. R., Gough, C., Guardans, R., Holoubek, I., Jansson, B., Koch, R., Kuylenstierna, J., Lecloux, A., Mackay, D., McCutcheon, P., Mocarelli, P., and Taalman, R. D. F.: Controlling persistent organic pollutants - what next?, Environ. Toxicol. Pharmacol., 6, 143-175, 1998.

Wania, F. and Mackay, D.: Tracking the distribution of persistent organic pollutants, Environ. Sci. Technol., 30, A390-A396, 1996.

Wania, F. and Daly, G. L.: Estimating the contribution of degradation in air and deposition to the deep sea to the global loss of PCBs, Atmos. Environ., 36, 5581-5593, 2002.

Wilford, B. H., Harner, T., Zhu, J. P., Shoeib, M., and Jones, K 
C.: Passive sampling survey of polybrominated diphenyl ether flame retardants in indoor and outdoor air in Ottawa, Canada: Implications for sources and exposure, Environ. Sci. Technol., 38, 5312-5318, doi:10.1021/es049260x, 2004.
Xiao, H., Li, N. Q., and Wania, F.: Compilation, evaluation, and selection of physical-chemical property data for alpha-, beta-, and gamma-hexachlorocyclohexane, J. Chem. Eng. Data, 49, 173185, doi:10.1021/je034214i, 2004. 